TEKNIK, 39 (1), 2018, 67-77

\title{
Analisa Kenaikan Tekanan Fluida Terhadap Tegangan Dan Fleksibilitas Pipa Blowdown A106 Grade A Berdasarkan ASME B31.3
}

\author{
Pekik Mahardhika*, Eko Julianto, Arie Indartono, George E. Kusuma \\ Program Studi Teknik Perpipaan, Jurusan Teknik Permesinan Kapal, Politeknik Perkapalan Negeri Surabaya, \\ Jl. Teknik Kimia, Kampus ITS, Sukolilo, Surabaya, Indonesia 60111
}

\begin{abstract}
Abstrak
Sistem blowdown pada PLTU digunakan untuk mengontrol dan membuang kandungan solid dalam sisa air pemanasan. Dampak negatif kenaikan tekanan fluida secara kontinyu adalah terjadinya deformasi pipa blowdown karena tegangan pipa melebihi nilai tegangan yang diijinkan. Artikel ini menyajikan hasil penelitian dalam menganalisa kenaikan tekanan fluida terhadap tegangan dan fleksibilitas pipa blowdown A106 Grade A berdasarkan ASME B31.3 Piping Process. Berdasarkan kriteria critical line, pipa blowdown A106 Grade A yang dikategorikan sebagai kategori B harus dikoreksi dengan metode sederhana. Fluida di dalam pipa blowdown telah mengalami kenaikan tekanan menjadi 322,55 psi dan bersifat turbulen. Berdasarkan ASME B31.3, tegangan dan fleksibilitas pipa blowdown masih di bawah nilai yang diijinkan dan sistem perpipaan dinyatakan aman.
\end{abstract}

Kata kunci: fleksibilitas; pipa blowdown; tegangan pipa akibat beban sustain; tekanan fluida

\begin{abstract}
[Title: Analysis of Fluid Pressure Increasement to Stress and Flexibility of Blowdown Pipe A106 Grade A Based On ASME B31.3] The blowdown system in the boiler of PLTU is useful for controlling and disposing of solid content in the remaining heating water. The negative effect of increased fluid pressure is pipe deformation because pipe stress exceeds allowable stress. This article deals with research results in analysing fluid pressure increasement to stress and flexibility of blowdown pipe A106 Grade A based on ASMEB31.3 Piping Process. Based on critical line criteria, blowdown pipe Al06 Grade A which is categorized as $B$ category should be corrected by simply methode. Fluid pressure in blowdown pipe is increased to 322,55 psi and become turbulent. Based on ASME B31.3, blowdown pipe stress and flexibility are still below the allowable value and the piping system is still safe.
\end{abstract}

Keywords: blowdown pipe; flexibility; fluid pressure; pipe stress due to sustained load

\section{Pendahuluan}

Boiler di PLTU beroperasi terus menerus sehingga perlu dilakukan proses blowdown secara berkala. Kandungan solid dalam sisa air pemanasan akan terbawa ke steam yang diproduksi. Apabila kandungan solid dalam air sisa pemanasan tinggi, maka kandungan solid di steam juga akan tinggi. Hal tersebut bisa menurunkan kualitas steam yang dihasilkan. Sistem blowdown dalam boiler berguna untuk mengontrol dan membuang kandungan solid dalam sisa air pemanasan agar tidak berlebih. Kandungan solid dalam sisa air pemanasan akan terbawa ke steam yang diproduksi.

\footnotetext{
${ }^{*}$ Penulis Korespondensi.

E-mail: pekikmahardhika@ppns.ac.id
}

Apabila kandungan solid dalam air sisa pemanasan tinggi, maka kandungan solid di steam juga akan tinggi. Hal tersebut bisa menurunkan kualitas steam yang dihasilkan. Selain itu, kandungan solid dalam air sisa pemanasan yang berlebih juga akan menyebabkan terjadinya kerak pada pipa, tube, dan drum sehingga selain peralatan tersebut cepat rusak, juga efisiensi boiler menurun karena kerak tersebut mengurangi area perpindahan panas (heat transfer area). Fluida dalam pipa mengalir memanfaatkan gravitasi. Pertemuan dua zat berbeda fase serta memiliki temperatur tinggi pada pipa dapat menimbulkan kenaikan tekanan yang menyerupai suatu pukulan. Dampak fenomena tersebut adalah menimbulkan getaran. Jika hal ini sering terjadi maka dapat menimbulkan deformasi pipa. Deformasi 


\section{TEKNIK, 39 (1), 2018, 68}

diakibatkan nilai tegangan pipa yang terjadi melebihi tegangan pipa yang diijinkan sesuai kode ASME B31.3. Artikel ini menyajikan hasil penelitian dalam menganalisa kenaikan tekanan fluida terhadap tegangan dan fleksibilitas pipa blowdown A106 Grade A berdasarkan ASME B31.3 Piping Process.

\section{Metode Penelitian}

Langkah dalam penelitian ini adalah penentuan kriteria critical line pipa, perhitungan kenaikan tekanan fluida, penentuan dan perhitungan tegangan pipa yang diijinkan, perhitungan thermal expansion, serta cek fleksibilitas pipa. Gambar 1 menunjukkan diagram alir langkah penelitian.

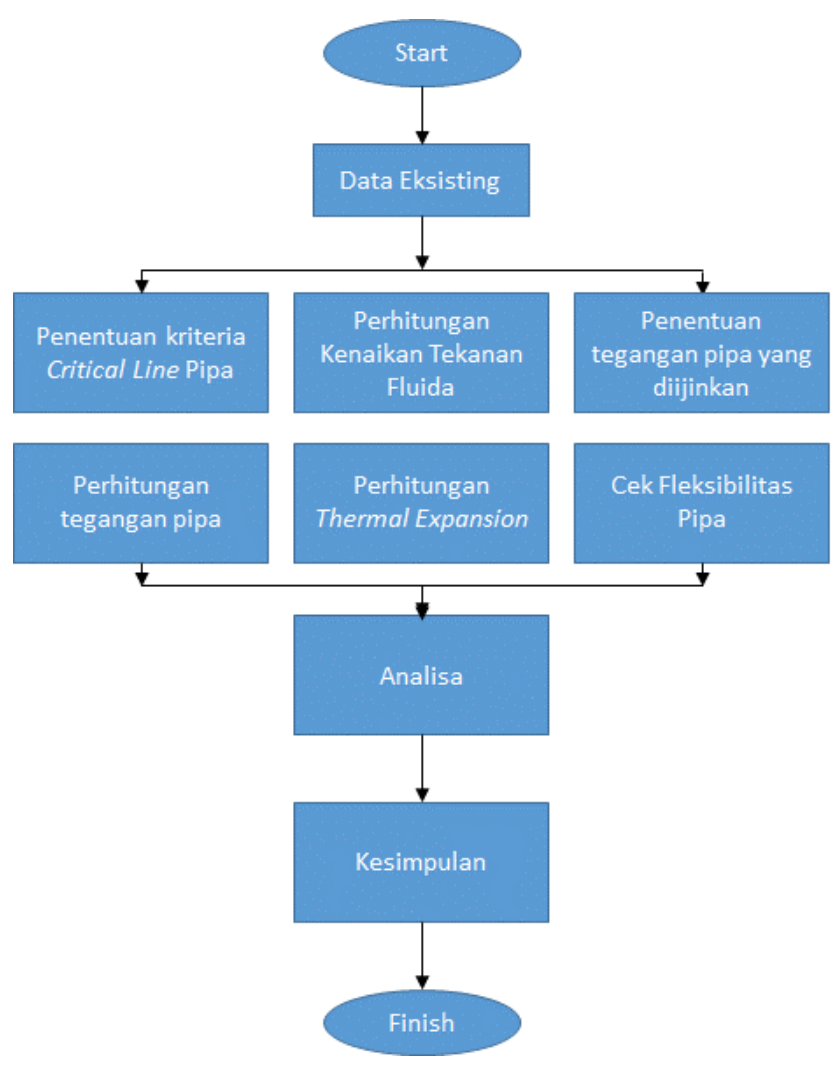

Gambar 1. Diagram Alir

Data spesifikasi pipa dan sifat fluida yang diperlukan untuk penelitian tercantum pada Tabel 1 dan Tabel 2. Sistem blowdown beroperasi setiap siklus 8 jam dengan design life 12 tahun. Isometri pipa blowdown ditunjukkan pada gambar 2 .

\subsection{Kriteria Critical Line}

Kriteria untuk critical line merupakan fungsi temperatur dan diameter pipa yang ditunjukkan dalam Gambar 3. Critical Piping adalah semua sistem pipa yang harus dipertimbangkan dalam analisa karena temperatur fluida dalam pipa memenuhi ketetapan dalam kriteria. Non critical piping adalah semua jalur pipa tidak dipertimbangkan atau diperhitungkan dalam piping stress analysis, karena temperatur fluida dalam pipa tidak memenuhi kriteria. Kriteria pada gambar 3 merupakan sistem pipa dihubungkan dengan nozzle static equipment (Chamsudi, 2005).

Tabel 1. Spesifikasi Pipa dan Insulasi yang diperlukan

\begin{tabular}{ll}
\hline Data & Spesifikasi \\
\hline Material Pipa & A106 Gr.A \\
NPS & 4 \\
Sch & 80 \\
$\mathrm{t}(\mathrm{in})$ & 0,337 \\
$\mathrm{t}(\mathrm{mm})$ & 8,56 \\
OD $(\mathrm{in})$ & 4,5 \\
OD $(\mathrm{mm})$ & 114,3 \\
$\mathrm{ID}(\mathrm{in})$ & 3,826 \\
$\mathrm{ID}(\mathrm{mm})$ & 97,18 \\
$\rho$ pipa $\left(\mathrm{lb} /\right.$ in $\left.^{3}\right)$ & 0,280 \\
Modulus Elastisitas Pipa (psi) & $27,7 \times 10^{6}$ \\
$\mathrm{t}$ insulasi (in) & 1,496 \\
Material Insulasi & Foam Glass \\
$\rho$ insulasi (lb/in $\left.{ }^{3}\right)$ & 0,049 \\
Thermal cofficient (mm/m) & 2 \\
Thermal cofficient (in/ft) & 0,028 \\
\hline
\end{tabular}

Tabel 2. Data Sifat Fluida yang diperlukan

\begin{tabular}{lll}
\hline Data & Nilai & Satuan \\
\hline $\begin{array}{l}\text { Tekanan Internal } \\
(\mathrm{P})\end{array}$ & 100 & $\mathrm{psi}$ \\
& 6,89 & $\mathrm{bar}$ \\
Laju massa & 2,22 & $\mathrm{~kg} / \mathrm{s}$ \\
fluida $(\mathrm{m})$ & & $\mathrm{kg} \cdot \mathrm{m} / \mathrm{s}$ \\
Viskositas $(\mu)$ & $1,00 \times 10^{-3}$ & $\mathrm{~N} / \mathrm{m}^{2}$ \\
$\begin{array}{l}\text { Bulk Modulus } \\
(\mathrm{K})\end{array}$ & $2,19 \times 10^{9}$ & $\mathrm{~F}$ \\
Temperatur (T) & 338 & $\mathrm{C}$ \\
\hline
\end{tabular}

\subsection{Bilangan Reynold}

Bilangan Reynold dipengaruhi kecepatan aliran, diameter pipa, massa jenis, dan viskositas fluida yang mengalir. Bilangan Reynold menggunakan rumus persamaan (Crane, 1982)

$$
\mathrm{Re}=\frac{\text { V.D. } \rho}{\mu}
$$

$\operatorname{Re}<2100$, Laminer

Re $>4000$, Turbulen 


\section{TEKNIK, 39 (1), 2018, 69}

Keterangan:

$\operatorname{Re}=$ Reynold Number

$\mathrm{V}=$ Kecepatan aliran $(\mathrm{m} / \mathrm{s})$

$\mathrm{D}=$ Diameter dalam pipa $(\mathrm{m})$

$\rho=$ Massa jenis fluida $\left(\mathrm{kg} / \mathrm{m}^{3}\right)$

$\mu=$ Viskositas fluida $(\mathrm{kg} \cdot \mathrm{m} / \mathrm{s})$

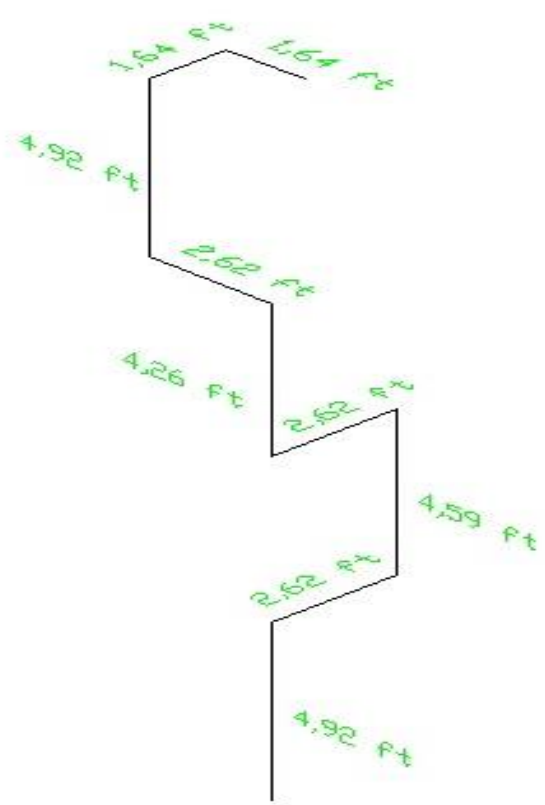

Gambar 2. Isometri pipa blowdown

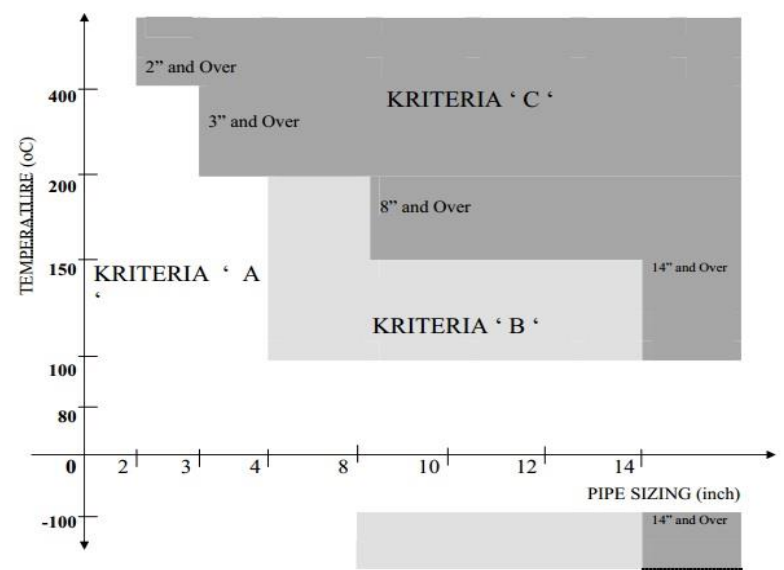

Gambar 3. Kriteria Critical line untuk static equipment (Chamsudi, 2005)

Keterangan:

Kriteria A : Tidak perlu dianalisa

Kriteria B : Harus dikoreksi dengan metode sederhana

Kriteria C : Detail analisa harus dihitung dengan komputer

\subsection{Kecepatan suara fluida}

Persamaan berikut digunakan untuk menghitung kecepatan suara fluida pada saat terjadi kenaikan tekanan (AutoPipe, 2008):

$$
a=\sqrt{\frac{\frac{K}{\rho}}{1+\left(\frac{K}{E}\right) \cdot\left(\frac{D}{e}\right)}}
$$

Keterangan:

$$
\begin{aligned}
& a=\text { Kecepatan suara fluida }(\mathrm{ft} / \mathrm{s}) \\
& \rho=\text { Massa jenis fluida }\left(\mathrm{lb} / \mathrm{ft}^{3}\right) \\
& \mathrm{K}=\text { Bulk Modulus }(\mathrm{psi}) \\
& \mathrm{E}=\text { Modulus Elastisitas Material (psi) } \\
& \mathrm{D}=\text { Diameter dalam pipa (in) } \\
& \mathrm{t}=\text { Tebal pipa (in) }
\end{aligned}
$$

\subsection{Tekanan Kejut}

Tekanan kejut akibat fluida dalam pipa menggunakan persamaan berikut (AutoPipe, 2008):

$$
\Delta p=\rho \cdot a . \Delta v
$$

Keterangan:

$$
\Delta \mathrm{p}=\text { Tekanan kejut (psi) }
$$

\subsection{Kenaikan Tekanan Fluida}

Kenaikan tekanan fluida di dalam pipa dihitung dengan menggunakan persamaan (AutoPipe, 2008):

$$
\Delta P=\text { TekananKerja }+\Delta p
$$

Keterangan:

$$
\Delta \mathrm{P}=\text { Kenaikan tekanan fluida }(\mathrm{psi})
$$

\subsection{Tegangan Pipa}

Tegangan pada pipa salah satunya meliputi tegangan akibat pembebanan sustain. Nilai tegangan pada pipa tidak boleh melebihi tegangan izin (ASME, 2014).

\subsubsection{Tegangan Akibat Beban Sustain}

$$
S L=\frac{F a x}{A m}+\frac{M b}{Z}+\frac{P . d o}{4 t} \leq S H
$$

Keterangan:

$$
\begin{aligned}
\mathrm{Fax}= & \text { Gaya aksial karena beban tetap }(\mathrm{lb}) \\
\mathrm{Am}= & \text { Luas permukaan pipa }\left(\mathrm{in}^{2}\right) \\
\mathrm{Mb}= & \text { Momen bending }(\mathrm{lb} . \mathrm{in}) \\
\mathrm{Z} & =\text { Section Modulus }\left(\mathrm{in}^{3}\right) \\
\mathrm{P} \quad= & \text { Tekanan dalam pipa }(\mathrm{psi}) \\
\mathrm{do} & =\text { Diameter Luar Pipa }(\mathrm{in}) \\
\mathrm{t} & =\text { Tebal Pipa (in) } \\
\mathrm{SL}= & \text { Tegangan Longitudinal (psi) } \\
\mathrm{SH}= & \text { Tegangan dasar yang diijinkan /Code } \\
& \text { Allowable stress (psi) berdasarkan tabel } \\
& \text { A1 ASME B31.3 }
\end{aligned}
$$

Untuk menentukan besar batasan tegangan (SH) dapat juga memilih nilai yang terkecil dari (Agustinus, 2009) : 


\section{TEKNIK, 39 (1), 2018, 70}

- Satu pertiga (1/3) dari specified minimum tensile strength (SMTS)

- Dua pertiga (2/3) dari specified minimum yield strength (SMYS)

Data SMTS dan SMYS ada di ASME B31.3 untuk menentukan besar batasan tegangan tersebut.

\subsubsection{Thermal expansion - stress \& force}

Thermal expansion dapat terjadi di antara semua fix point di sistem perpipaan. (EngineeringToolbox, 2017). Formula untuk menghitung thermal expansion sebagai berikut (Kannapan, 1986):

\section{Pipe expansion}

$$
\Delta L=\beta . L . \Delta T
$$

Thermal force

$$
F=E . \alpha . A
$$

Thermal stress

$$
\sigma d t=E . \beta . \Delta T
$$

Keterangan:

$$
\begin{array}{ll}
\beta & =\text { koefisien ekpansi termal (in/in.F) } \\
\mathrm{L} & =\text { Panjang pipa }(\mathrm{ft}) \\
\Delta \mathrm{T} & =\text { Perbedaan temperatur }(\mathrm{F}) \\
\mathrm{F} & =\text { Thermal Force }(\mathrm{lb}) \\
\mathrm{E} & =\text { Modulus Elastisitas }(\mathrm{psi}) \\
\alpha & =\text { Linier thermal expansion }(\mathrm{in} / 100 \mathrm{ft}) \\
\mathrm{A} & =\text { Luas permukaan pipa }\left(\mathrm{in}^{2}\right)
\end{array}
$$

Pada tahap selanjutnya terdapat metode untuk mengecek fleksibilitas sistem perpipaan. Tentang pertimbangan kekuatan, reaction hazard, dan service hazard, dan beberapa pendapat dibentuklah batas ukuran pipa, tekanan, dan temperatur. Pendekatan sistem perpipaan yang dibutuhkan untuk dianalisa fleksibilitasnya sebagai berikut (Kellog, 1956):

a. Maksimum nominal temperatur operasi material melebihi $800 \mathrm{~F}$

b. Service Pressure melebihi 15 psi

c. Nominal Pipe Size melebihi 6 inch Jika,

$$
\frac{D \cdot y}{(L-U)^{2}} \leq \frac{30 . S A}{E a}
$$

Maka sistem pipa fleksibel (Kannapan, 1986):

Keterangan:

$$
\begin{aligned}
\mathrm{D}= & \text { Nominal Pipe Size }(\mathrm{inch}) \\
\Delta= & \text { Resultant total displacement }(\mathrm{inch}) \\
\mathrm{L} & =\text { Developed lenght } \text { di antara } \text { anchor }(\mathrm{ft}) \\
\mathrm{U}= & \text { Jarak anchor }(\mathrm{ft}) \\
\mathrm{S}_{\mathrm{A}}= & \text { Allowable stress range }(\mathrm{psi}) \\
\mathrm{E}_{\mathrm{a}}= & \text { Modulus Elastisitas pada kondisi dingin } \\
& (\mathrm{psi})
\end{aligned}
$$

Jika,

$$
\frac{D . \Delta}{(L-U)^{2}} \leq K
$$

Maka sistem pipa fleksibel (Senthilkumar, 2015)

Keterangan:

$$
\begin{aligned}
& \mathrm{D}=\text { Diameter luar pipa }(\mathrm{mm}) \\
& \Delta=\text { Resultant displacement }(\mathrm{mm}) \\
& \mathrm{L}=\text { Developed lenght di antara anchor }(\mathrm{mm}) \\
& \mathrm{U}=\mathrm{Jarak} \text { anchor }(\mathrm{m}) \\
& \mathrm{K}=208,3
\end{aligned}
$$

Tabel 3 merupakan stress range reduction factors berkaitan dengan jumlah siklus suatu sistem perpipaan.

Tabel 3. Stress Range Reduction Factors (ASME, 1998)

\begin{tabular}{lc}
\hline \multicolumn{1}{c}{$\begin{array}{c}\text { Number of equivalent full } \\
\text { temperatur cycles } \mathbf{~}\end{array}$} & f \\
\hline 7000 dan dibawahnya & 1,0 \\
$7000-14000$ & 0,9 \\
$14000-22000$ & 0,8 \\
$22000-45000$ & 0,7 \\
$45000-100000$ & 0,6 \\
100000 dan di atasnya & 0,5 \\
\hline
\end{tabular}

Pipa blowdown berada di jalur pulsating line yang sehingga nilai frekuensi alami harus lebih besar dari 8 cps untuk mencegah adanya resonansi pada pipa (Mahardhika, 2017).

\section{Hasil dan Pembahasan}

Pada Kriteria Critical Line spesifikasi pipa blowdown yang sesuai Tabel 1 dikaitkan dengan gambar 2, maka pipa dikategorikan kriteria B yang artinya harus dikoreksi dengan metode sederhana. Pipa blowdown A106 Gr.A NPS 4" termasuk critical line.

Dalam menghitung kenaikan tekanan dalam pipa menggunakan formula 1 sampai 4 . Pada aliran fluida yang melewati pipa blowdown terjadi kenaikan tekanan menjadi 322,55 psi. Aliran fluida tersebut bersifat turbulen $(\operatorname{Re}>4000)$. Tabel 4 memuat perhitungan kenaikan tekanan fluida.

Tabel 4. Perhitungan Kenaikan Tekanan Fluida

\begin{tabular}{cccc}
\hline No & Data & Nilai & Keterangan \\
\hline 1 & $\mathrm{Re}$ & 56617 & $\mathrm{Re}>4000$, Turbulen \\
2 & $a$ & 4433,6 & $\mathrm{ft} / \mathrm{s}$ \\
3 & $\Delta \mathrm{p}$ & 222,55 & $\mathrm{psi}$ \\
4 & $\Delta \mathrm{P}$ & 322,55 & $\mathrm{psi}$ \\
\hline
\end{tabular}

Pada tegangan akibat beban sustain, batasan tegangan/tegangan yang diijinkan pada pipa akibat 


\section{TEKNIK, 39 (1), 2018, 71}

primary stress yaitu akibat beban sustain dinamakan code allowable stress. Perhitungan batasan tegangan yang diijinkan berdasarkan ASME B31.3 tabel A1, SMTS, dan SMYS ditunjukkan pada Tabel 5, 6, dan 7.

Tabel 5. Tegangan yang diijinkan (SH) akibat beban sustain (SL) berdasarkan tabel A1 ASME B31.3

\begin{tabular}{|c|c|c|c|}
\hline No & Data & Nilai & Satuan \\
\hline 1 & $\mathrm{SH}$ & 16000 & psi \\
\hline 2 & SL sebelum & 8539,581 & psi \\
\hline 3 & SL setelah & 9863,04 & psi \\
\hline
\end{tabular}

Tabel 6. Tegangan yang diijinkan (SH) akibat beban sustain (SL) berdasarkan SMTS

\begin{tabular}{llll}
\hline No & \multicolumn{1}{c}{ Data } & \multicolumn{1}{c}{ Nilai } & Satuan \\
\hline 1 & SH & 16000 & $\mathrm{psi}$ \\
2 & SL sebelum & 8539,581 & $\mathrm{psi}$ \\
3 & SL setelah & 9863,04 & $\mathrm{psi}$ \\
\hline
\end{tabular}

Tabel 7. Tegangan yang diijinkan (SH) akibat beban sustain (SL) berdasarkan SMYS

\begin{tabular}{lllc}
\hline No & \multicolumn{1}{c}{ Data } & \multicolumn{1}{c}{ Nilai } & Satuan \\
\hline 1 & SH & 20000 & psi \\
2 & SL sebelum & 8539,581 & psi \\
3 & SL setelah & 9863,04 & psi \\
\hline
\end{tabular}

Tabel 5 sampai Tabel 7 menunjukkan bahwa pipa memiliki range tegangan diijinkan sebesar 1600020000 psi. Nilai tegangan yang diijinkan/code allowable stress diambil yang terkecil yaitu 16000 psi. Hasil perhitungan menunjukkan bahwa nilai tegangan sebelum kenaikan tekanan 8539,581 psi dan setelah terjadi kenaikan tekanan 9863,04 psi. Tegangan menunjukkan terjadi kenaikan sebesar 1323,459 psi. Nilai tegangan akibat beban sustain pada pipa blowdown tersebut tidak melebihi tegangan yang diijinkan ASME B31.3.

Pada hasil perhitungan Thermal Expansion stress \& force dijabarkan sebagai berikut:

$$
\begin{aligned}
& \text { Pipe Expansion } \\
& \begin{aligned}
& \Delta L=\beta . L . \Delta T \\
&=7,1 \times 10^{-6} \mathrm{in} / \mathrm{in} . \mathrm{F} \times 30,076 \mathrm{ft} \times(338-70) \mathrm{F} \times \\
& 12 \mathrm{in} / \mathrm{ft} \\
&= 0,686 \mathrm{in}
\end{aligned}
\end{aligned}
$$

$$
\begin{aligned}
& \text { Thermal Force } \\
& \qquad \begin{aligned}
F & =\text { E. } \alpha \cdot A \\
& =27,7 \times 10^{6} \mathrm{lb} / \mathrm{in}^{2} \times \frac{28}{100 \times 12} \frac{\mathrm{im}}{\mathrm{in}} \times 3,17 \mathrm{in}^{2} \\
& =204800 \mathrm{lb}
\end{aligned}
\end{aligned}
$$

$$
\begin{aligned}
& \text { Thermal Stress } \\
& \begin{aligned}
\sigma d t & =E . \beta . \Delta T \\
& =27,7 \times 10^{6} \mathrm{lb}_{\mathrm{in}}^{2} \times 7,1 \times 10^{-6} \mathrm{in} / \mathrm{in} . \mathrm{F} \times(338- \\
& 70) \mathrm{F} \\
& =52707,56 \mathrm{psi}
\end{aligned}
\end{aligned}
$$

Pipa blowdown termasuk kategori untuk dianalisa karena tekanan fluida melebihi 15 psi, sehingga hasil perhitungan fleksibilitas pipa dijabarkan sebagai berikut:

Cara 1:

$$
\begin{aligned}
& \Delta \mathrm{x}=(0,5-0,8) \mathrm{m} \times 2 \mathrm{~mm} / \mathrm{m} \\
&=-0,6 \mathrm{~mm}(-0,023 \mathrm{in}) \\
& \Delta \mathrm{y}=(1,5+1,3+1,4+1,5) \mathrm{m} \times 2 \mathrm{~mm} / \mathrm{m} \\
&= 11,4 \mathrm{~mm}(0,45 \mathrm{in}) \\
& \Delta \mathrm{z}=(0,5+0,8+0,8) \mathrm{m} \mathrm{x} 2 \mathrm{~mm} / \mathrm{m}=4,2 \mathrm{~mm} \\
&(0,165 \mathrm{in}) \\
& \Delta= \sqrt{(-0,6)^{2}+(11,4)^{2}+(4,2)^{2}} \\
&= 12,16 \mathrm{~mm}(0,478 \mathrm{in}) \\
& \mathrm{L}= 9,9 \mathrm{~m}(30,076 \mathrm{ft}) \\
& \mathrm{U}= \sqrt{(1,3)^{2}+(5,7)^{2}+(2,1)^{2}} \\
&= 6,21 \mathrm{~m}(0,24 \mathrm{in}) \\
& D . \Delta \frac{(L-U)^{2}}{(L-K} \\
& \frac{114,3 \cdot 12,16}{(9,9-6,21)^{2}} \leq 208,3 \\
& 105,77 \leq 208,3
\end{aligned}
$$

Sehingga pipa tersebut fleksibel dan tidak perlu dilakukan formal analysis.

Cara 2:

$$
\begin{aligned}
& \Delta \mathrm{x}=(1,64-2,624) \mathrm{ft} \mathrm{x} 0,028 \mathrm{in} / \mathrm{ft} \\
& =-0,027552 \text { in } \\
& \Delta \mathrm{y}=(4,92+4,16+4,592+4,92) \mathrm{ft} \times 0,028 \mathrm{in} / \mathrm{ft} \\
& =0,52059 \text { in } \\
& \Delta \mathrm{z}=(1,64+2,624+2,624) \mathrm{ft} \times 0,028 \mathrm{in} / \mathrm{ft} \\
& =0,192864 \mathrm{in} \\
& \Delta=\sqrt{(-0,027552)^{2}+}(0,52059)^{2}+(0,192864)^{x} \\
& =0,5558 \text { in } \\
& \mathrm{L}=30,076 \mathrm{ft} \\
& \mathrm{U}=\sqrt{(4,624)^{2}+}(18,592)^{2}+(6,888)^{4} \\
& =20,280 \mathrm{ft} \\
& \mathrm{S}_{\mathrm{c}}=16000 \mathrm{psi} \\
& \mathrm{S}_{\mathrm{h}}=16000 \mathrm{psi} \\
& \mathrm{N}(\text { jumlah siklus })=\frac{24}{\mathrm{~g}} \times 365 \times 12=13140 \\
& \text { f } \quad=0,9 \text { (untuk siklus 7000-14000) } \\
& \mathrm{S}_{\mathrm{A}} \quad=\mathrm{f}\left(1,25 \cdot \mathrm{S}_{\mathrm{c}}+0,25 \cdot \mathrm{S}_{\mathrm{h}}\right) \\
& =0,9(1,25 \cdot 16000+0,25.16000) \\
& =21600 \mathrm{psi} \\
& \frac{D . y}{(L-U)^{2}} \leq \frac{30 . S A}{E a} \\
& \frac{4.0,5558}{(30,076-20,28)^{2}} \leq \frac{30.21600}{27,7 \times 10^{6}} \\
& 0,0231 \leq 0,0234
\end{aligned}
$$




\section{TEKNIK, 39 (1), 2018, 72}

Sehingga pipa tersebut fleksibel dan tidak perlu dilakukan formal analysis.

Perhitungan frekuensi alami dengan batasan defleksi sebesar 1/8 inch, sehingga didapat nilai frekuensi alami $f n=\frac{3,12}{\sqrt{1 / a}}=8,8 \mathrm{cps}$

Data menunjukkan bahwa nilai frekuensi alami lebih besar dari $8 \mathrm{cps}$.

\section{Kesimpulan}

Analisa kenaikan tekanan fluida terhadap tegangan dan fleksibilitas pipa blowdown A106 Grade A menunjukkan bahwa terjadi kenaikan tekanan fluida sebesar 322,55 psi dan fluida bersifat turbulen. Fleksibilitas pipa masih di bawah nilai yang diijinkan sehingga pipa masih fleksibel terhadap displacement yang terjadi dan tidak perlu dilakukan formal analysis. Pengecekan tegangan pipa akibat beban sustain setelah terjadi kenaikan tekanan fluida menunjukkan bahwa masih berada di bawah tegangan ijin (16000 psi), sehingga sistem perpipaan blowdown masih dinyatakan aman berdasarkan ASME B31.3.

\section{Daftar Pustaka}

Agustinus, D. (2009). Pengantar Piping Stress Analysis. Jakarta: Entry Augustino Publisher
ASME. (1998). ASME B\&PV Section III. USA: American Society Mechanical Standard

ASME. (2014). ASME B31.3 Piping Process. USA: American Society of Mechanical Engineering

AutoPipe (2008). Example Case System Water Hammer. USA: Bentley

Chamsudi. (2005). Diktat-Piping Stress Analysis. Diunduh dari https://www.scribd.com/document/259036537/Di ktat-Pipe-Stress-Analysis

Crane. (1982). Flow of Fluids Through Valve, Fittings, and Pipe, Technical paper 410M (p. 4). New York: Crane Co.

EngineeringToolbox. (2017). Engineering toolbox. Diakses dari www.engineeringtoolbox.com

Kannapan, S. (1986). Introduction to Pipe Stress Analysis. Canada: John Wiley \& Sons

Kellog, M. W. (1956). Design of Piping Systems. USA: Pullman Power Products

Senthilkumar, M. S. (2015). Analysis of piping layout under static load in petrochemical industries. Int. Journal of Applied Sciences and Engineering Research, 4 (2), 240-249

Mahardhika, P. (2017). Penentuan allowable span pipa SLF berdasarkan tegangan, defleksi, frekuensi alami. Jurnal IPTEK, 21 (2), 27-34 